\title{
Self-limiting nephrotic range protienuria associated with dengue haemorrhagic fever
}

\author{
Egodage UK, Priyankara WPGP, Jayanthissa WMVCT, Weerarathna TP \\ University Medical Unit, Teaching Hospital, Karapitiya, Galle, Sri Lanka.
}

Correspondence: Dr. Udari K Egodage

e-mail: kaushiegodage@gmail.com

\section{Introduction}

Dengue fever (DF) is the most prevalent mosquitoborne viral disease in South and Southeast Asia (1). Association of gross nephrotic-range proteinuria with DF has not been reported in Sri Lanka. We report a female with dengue haemorrhagic fever (DHF) complicated with acute liver failure and selflimiting, nephrotic-range proteinuria

\section{Case Report}

A 33 year-old previously healthy female presented with fever, vomiting, arthralgia of three days. On admission, she had pulse rate of $92 \mathrm{bpm}$ and blood pressure of 100/70 $\mathrm{mmHg}$.
On the fourth day of fever, her blood pressure revealed a significant drop to $80 / 70 \mathrm{mmHg}$. Her initial full blood count revealed a platelet count of 89 x $10^{9} / \mathrm{L}$ and clinical diagnosis of DHF was made and she was managed with intravenous fluids according to WHO guidelines. On admission urine ward test revealed no proteinuria. Initial serum alanine transaminase(ALT) and aspartate transaminase $(\mathrm{AST})$ were $800 \mathrm{u} / \mathrm{L}$ and $3100 \mathrm{u} / \mathrm{L}$. Repeat ALT, AST later rose up to $3900 \mathrm{u} / \mathrm{L}$ and $15000 \mathrm{u} / \mathrm{L}$ respectively (Table 1) with international normalized ratio(INR) of 1.79. Diagnosis of grade 2 hepatic encephalopathy was made and N-Acetyl Cysteine and liver failure regimen was commenced. On the fifth day, she became dyspnoeic with bilateral pleural effusions and ascites.

Table1: Laboratory investigations

\begin{tabular}{lllllllllll}
\hline Day of Fever & D3 & D4 & D5 & D6 & D7 & D8 & D9 & D10 & D11 & D14 \\
\hline Plt $($ x 10 $/ \mathrm{L})$ & 89 & 10 & 23 & 31 & 44 & 129 & 135 & 144 & 191 & 299 \\
HCT $(\%)$ & 37.5 & 49.9 & 39 & 42.5 & 39.1 & 37.6 & 33.2 & 34 & 33 & 33.5 \\
WBC $\left(\times 10^{6} / \mathrm{L}\right)$ & 3.06 & 4.3 & 9.9 & 10.3 & 7.4 & 7.3 & 8.1 & 7.6 & 7.1 & 7.8 \\
Creatinine (mol/L) & - & 103 & 110 & 133 & & 73 & - & - & - & 76 \\
ALT (U/L) & - & 800 & 3900 & 2020 & 1010 & 148 & - & - & - & 68 \\
AST (U/L) & - & 3100 & 15000 & 8800 & 1580 & 139 & - & - & - & 70 \\
Albumin (g/dL) & - & - & - & - & 2.39 & 2.36 & - & - & - & 3.5 \\
INR & 1.0 & - & 1.79 & 1.55 & 1.0 & - & - & - & - & - \\
UWT albumin & 0 & - & - & - & $4+$ & $4+$ & $2+$ & $1+$ & 0 & 0 \\
PCR & - & - & - & - & 13.4 & - & - & 1.47 & - & - \\
Ca ${ }^{+2}(\mathrm{mg} / \mathrm{dL})$ & - & - & 8.4 & 7.2 & - & - & - & - & - & - \\
CRP (mg/dL) & 19.8 & - & - & - & - & - & 47.1 & - & - & - \\
\hline
\end{tabular}

D - Day of fever, WBC - white blood cells, HCT - Hematocrit, Plt - platelet count, Creatinine - serum creatinine, ALT - alanine transaminase, AS aspartat e aminotransferase, INR - Interanational normalization ratio, UWT alb - Urine ward test for albumin, PCR protein/creatinine ratio 
During the next 48 hours she improved with rising platelet counts and decreasing liver enzymes. IgM and IgG against dengue virus (DENV) were positive. Bilateral pleural effusions and ascites remained unresolved after recovering from critical phase. Serum albumin tested on the seventh day of illness was low $(2.26 \mathrm{~g} / \mathrm{dL})$. Urine ward test on the same day revealed gross $(4+)$ proteinuria and the urine protein to creatinine ratio (PCR) was in the nephrotic range $13.44 \mathrm{~g}$ protein $/ \mathrm{g}$ creatinine $(>3.5$ nephrotic range). Gross $(4+)$ proteinuria persisted up to day ten and cleared gradually. On the fourteenth day, urine albumin was absent and repeat serum albumin was $3.5 \mathrm{~g} / \mathrm{dL}$.

Hypoalbuminemia associated with gross proteinuria was treated with albumin infusions. After resolution of gross proteinuria, she was discharged on the fourteenth day. Urine analysis carried out two weeks later on the follow-up visit revealed normal PCR, AST, ALT and serum albumin levels.

\section{Discussion}

Plasma leakage leading to DHF is the most dreadful complication in DF. Proteinuria is sometimes observed in DF and DHF, typically without evidence of renal involvement.

Hanh et al. measured urine albumin to creatinine ratios (UACRs) daily in children with suspected DF in Vietnam and found that low-level albuminuria is common in relatively mild DF (2). They observed that peak values reach around the critical period for dengue-associated plasma leakage, but concluded it is unlikely to be useful for early diagnosis or risk prediction (2).

In contrary, Farhad et al. found that peak UACR could potentially predict DHF in patients with dengue requiring close monitoring (3). In their series, patients with uncomplicated DF did not develop significant proteinuria, while $96 \%$ of patients with DHF had significant proteinuria. They observed that maximum proteinuria coincides with defer vescence and reported a statistically significant association of higher degree of thrombocytopenia with significant proteinuria (3). In their series, proteinuria was self-limiting and resolved with recovery from fever.
Renal biopsies in patients with DHF have showed histology similar to IgA nephropathy (4). Identification of soluble immune complex in DHF specific for DENV in serum has been reported indicating that immune complexes get deposited in vascular and glomerular tissue leading to proteinuria (5).

Nephrotic range proteinuria is rarely been reported in patients with DHF $(6,7)$. Our patient had no manifestations of renal damage, such as rising serum creatinine, haematuria or urinary casts but, only had transient gross nephrotic-range proteinuria and significant transient hypoalbuminemia. The half-life of serum albumin is around 21 days (8). Therefore infective or inflammatory disorders with liver involvement lasting for more than three weeks can lead to hypoalbuminemia. This patient had gross proteinuria associated with low serum albumin on the seventh day of fever, indicating urinary loss and plasma leakage of albumin as the most likely causes for low serum albumin level.

Delayed resolution of pleural effusions and ascites with rise in urine protein excretion prompted us to test for serum albumin and treatment with albumin infusions lead to rapid recovery of effusions and ascites. Hypoalbuminemia is a common feature in DHF but, we report this patient to highlight that nephrotic range proteinuria is a rare, self-limiting complication of DHF. It should be suspected when there is a delay in the resolution of ascites and pleural effusion. Albumin infusions given even after recovering from critical phase of DHF to treat ascites and pleural effusions associated with severe hypoalbuminemia can restore reduced plasma oncotic pressure secondary to transient urinary protein loss and expedite recovery.

\section{References}

1. Simmons CP, Farrar JJ, Van VCN, Wills B. Dengue. N Engl J Med 2012; 366: 1423-32.

2. Hanh Tien NT, Lam PK, Duyen HT, et al. Assessment of microalbuminuria for early diagnosis and risk prediction in dengue infections. PLoS One 2013; 8: e545538.

3. Farhad F, Vasanwala FF, Tun-Linn T, et al. Predictive Value of Proteinuria in Adult Dengue Severity. PLoSNegl Trop Dis. 2014; 8: e2712. 
4. Upadhaya BK, Sharma A, Khaira A, Dinda AK, Agarwal SK, Tiwari SC: Transient IgA nephropathy with acute kidney injury in a patient with dengue fever. Saudi J Kidney Dis Transpl2010,21:521-5.

5. Brandt WE, Chiewslip D, Harris DL, Russell PK. Partial purification and characterization of a dengue virus soluble complement-fixing antigen. J Immunol 1970, 105:1565-8.

6. Hutspardol S, Prommalikit O, Upiya N, Chataroopwijit J, Khemakanok K, Assadamongkol K. Heavy proteinuria following dengue hemorrhagic fever. Southeast Asian J Trop Med Public Health 2011; 42: 579-82.
7. Hebbal P, Darwich Y, Fong J, Hagmann SH, Purswani MU. Nephrotic-range proteinuria in an eight-year-old traveler with severe dengue: Case report and review of the literature Travel Med Infect Dis. 2016; 14: 45-8.

8. Liumbruno GM, Bennardello F, Lattanzio A, Piccoli P, Rossettias G; Italian Society of Transfusion Medicine and Immunohaematology . Recommendations for the use of albumin and immunoglobulins. Blood Transfus. 2009; 7: 216-34. 